\title{
Effectiveness Analysis Of Cooling Effect Of Crushed Stone Roadbed Fei Jiang ${ }^{1, a)}$, Xue Song Mao ${ }^{1, b)}$, YaJun Xiao ${ }^{1, c)}$ \\ ${ }^{1}$ School of highway, Chang'an University, Xi'an 710064, China. a)1414628449@qq.com, ${ }^{\text {b) } x u e s o n g m a o @ y a h o o . c o m . c n, ~}{ }^{\text {c)}} 276908628 @ q q . c o m$
}

Keywords: permafrost; gravel subgrade; cooling effect; temperature field

\begin{abstract}
In the permafrost subgrade protection measures, which is the most representative of the gravel roadbed cooling scheme. The test project is parallel to the Qinghai Tibet highway on the basis of temperature, dynamic monitoring of subgrade, through field test results of temperature change compared with that of ordinary embankment and gravel roadbed in the analysis of the cooling effect of crushed rock subgrade. The results show that the gravel roadbed has a cooling effect, to some extent, has wide application prospect in permafrost area road.
\end{abstract}

\section{INTRODUCTION}

In permafrost regions, annual average temperature is low, the changing climate, this area of highway subgrade affected by seasonal climate, roads often appear frost heave and thaw settlement, frost, crack and so on, which makes the performance of the road declined sharply, which not only caused the highway maintenance cost is greatly improved, and seriously restricts the development of highway construction in permafrost regions. While the gravel roadbed is an important active permafrost protection measures, many scholars have carried out experimental research and numerical analysis on the gravel roadbed ${ }^{[1-3]}$. At present, the cooling effect of crushed rock subgrade in the laboratory research stage, through the analysis of the test results of the cooling effect is relatively small. Based on this, this study through a section of the Qinghai Tibet highway subgrade engineering test, monitoring the temperature change, the cooling effect of crushed rock subgrade evaluation, so as to provide reference for roadway engineering design and performance evaluation.

\section{TEST ENGINEERING STATUS}

\section{Environmental And Climatic Characteristics Along The Test Project}

The Qinghai Tibet Plateau belongs to the alpine continental climate, cold and dry, thin air, solar radiation is extremely strong. For many years the average minimum temperature along the Qinghai Tibet highway is -14.5 to -17.4 degrees, the average maximum temperature for -6.8 to 8.1 DEG C, the annual average ground temperature of -20.5 to 14.9 DEG C, the annual average temperature of $-2.0 \sim-6.9$ degree Celsius. Average annual temperature was from the north the South gradually increased.

\section{Test Engineering}

The test project is located in the Qinghai Tibet highway near the five beams of K3012 side (along the Golmud to Lhasa direction), in parallel with the Qinghai Tibet highway, see Figure 1 Test Engineering open terrain, micro cross slope, cross slope cutting line, left right high low; the vegetation is sparse, dense local, no frost crack; elevation above $4500 \mathrm{~m}$. Located in the permafrost area. 


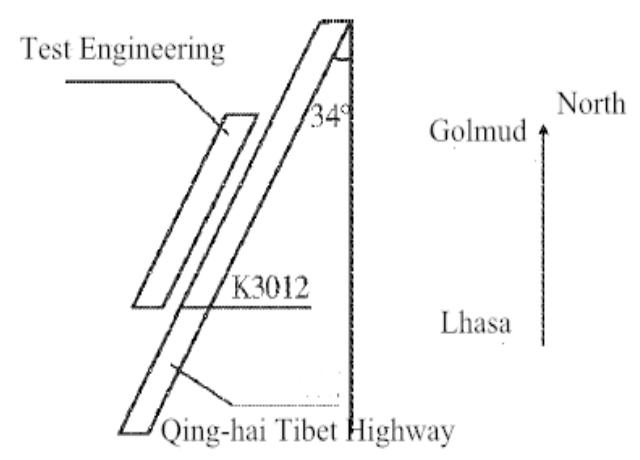

FIGURE 1. Schematic diagram of the plane position of the test project

\section{Test Results Analysis}

After the completion of the project, two months after the stability of the temperature monitoring, every 10 days, once again, through the gravel roadbed and ordinary roadbed temperature contrast, analysis of gravel roadbed cooling effect.

\section{Roadbed Temperature Varies With Depth In Different Time}

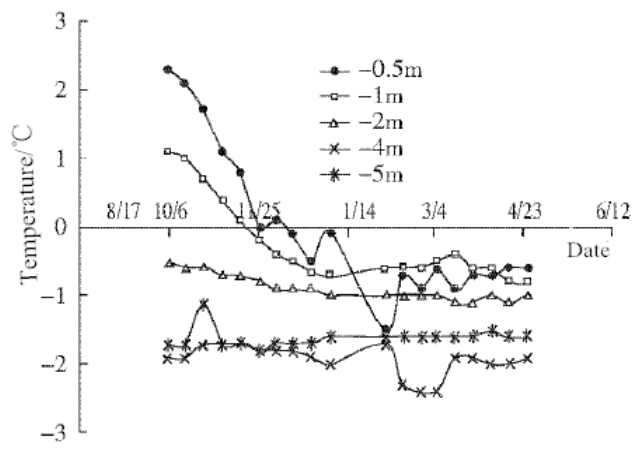

(a)Macadam Subgrade

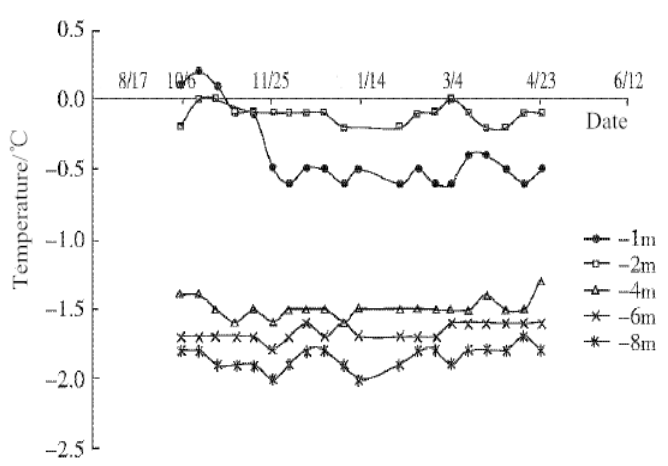

(b)Common Subgrade

FIGURE 2. Variation of soil temperature at different depths in different time

From figure 2 (a) shows that in the gravel roadbed in greater depth, distance from the ground, subgrade temperature changes more gently on the ground below $4 \mathrm{~m}$ depth, the internal temperature of roadbed stable and did not change significantly, but near the surface, large temperature changes, the temperature fell faster, from figure 2 (see B) ordinary subgrade temperature changes within the entire range of relatively flat, the layers of the temperature change is not obvious, that the general internal temperature of soil subgrade is less affected by ambient temperature. Thus, the gravel base table under temperature variation affected than the outside temperature to the base path, and more from the surface near the gravel roadbed better cooling effect in. Figure 2 (a) can also be seen, in the different depth of the earth's surface, the lowest temperature time is not consistent, but changes with the increase of depth, the temperature change has a certain lag.

Because of the influence of the climate change, the gravel roadbed shows the two sides: when the outside temperature is lower, the gravel road base temperature is low; when the outside air temperature is high, the gravel base temperature is higher

\section{The Comparison Of The Gravel Subgrade And Common Subgrade}

Take the maximum and minimum values of the depth of the gravel subgrade and the common subgrade center at all time periods, draw the temperature envelope, as shown in figure 3 


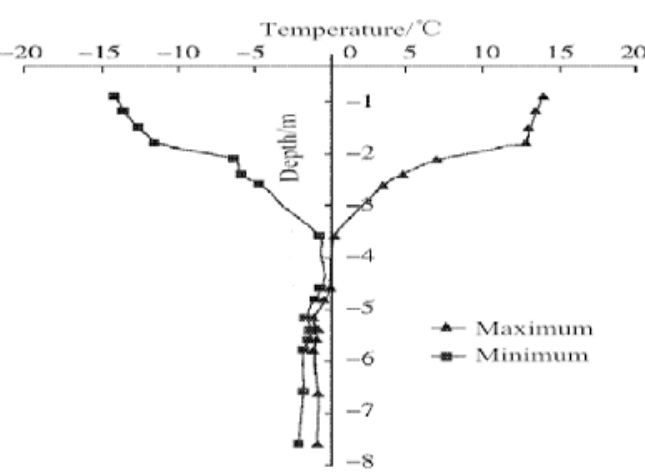

(a)Common Subgrade

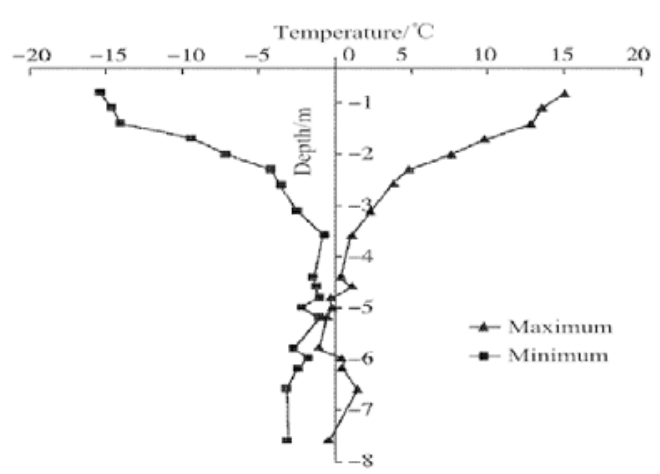

(b)Macadam Subgrade

FIGURE 3. Envelope diagram of roadbed temperature

From Figure 3 (a) shows that ordinary embankment in depth below $4 \mathrm{~m}$, soil temperature difference between maximum and minimum value of smaller, indicating little change, the soil temperature in this range tends to be stable. And figure 3 (b), the gravel roadbed in the deep $5 \mathrm{~m}$ temperature difference between maximum and minimum value that is smaller. In this part of the soil temperature, and the temperature change in the remaining layers of the gravel roadbed is obvious, therefore, the gravel roadbed temperature is affected by the outside temperature is larger than ordinary roadbed.

\section{Subgrade Temperature Changes With Depth}

In the experimental area, according to meteorological data, the average temperature is the lowest in February, the average temperature is the highest in August, compared with the average temperature and the average temperature of the roadbed in the highest monthly temperature change law, as shown in figure 4.

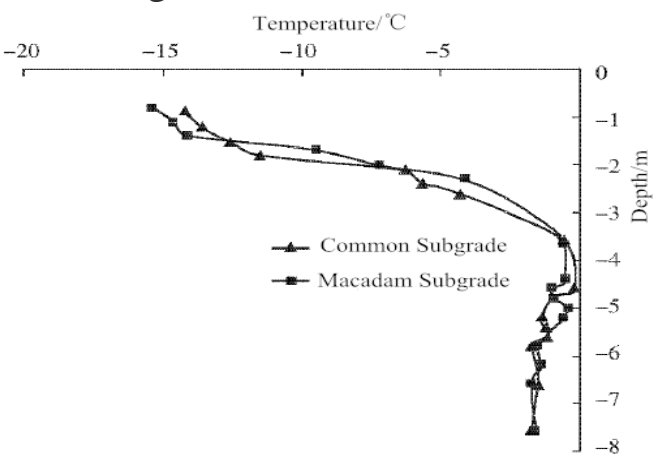

(a)Lowest Temperature Month

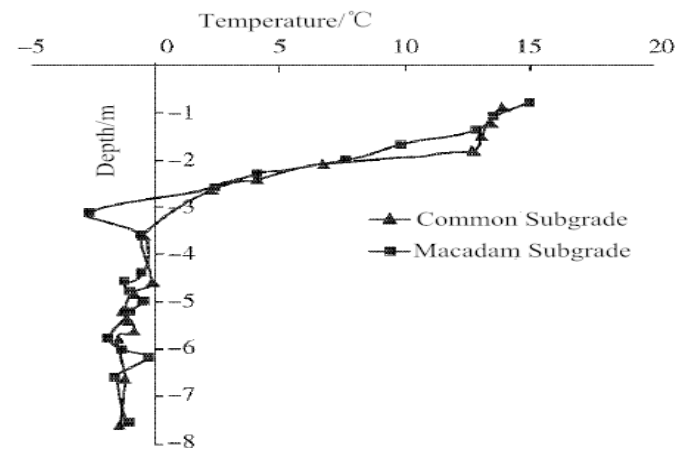

(b)Highest Temperature Month

FIGURE 4. Curves of subgrade temperature with depth

According to figure 4 (a) shows that the gravel roadbed temperature change with depth on the whole to radical is higher than that of the common road, in different depth of soil temperature were less than ordinary subgrade temperature. From figure 4 (b) shows that the gravel roadbed temperature change with depth on the whole lower than ordinary roadbed, ordinary the subgrade layers temperature is slightly larger than the internal temperature of the gravel roadbed soil and gravel roadbed were less common subgrade soil temperature in cold and warm season temperature, indicating the cooling effect of crushed rock subgrade has certain compared to ordinary embankment.

\section{The Comparison Of The Difference Between The State And The General Subgrade}

The average temperature difference between the ordinary roadbed and crushed stone roadbed is one year. The temperature of the same year is subtracted from the temperature of the previous year and compared with the difference map, as shown in figure 5. 


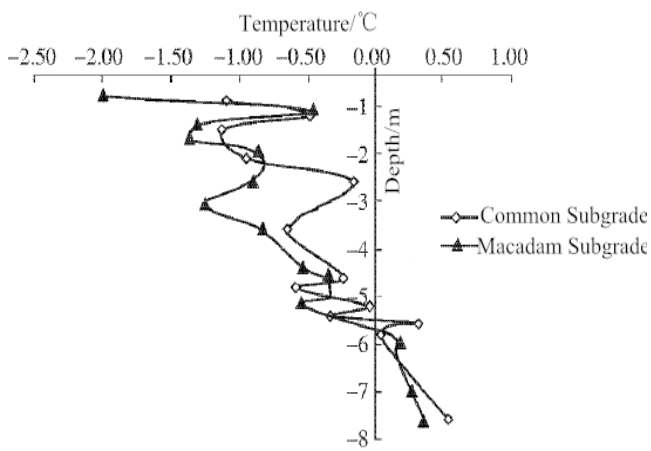

FIGURE 5. Comparison of the difference between the state of the common subgrade and the crushed stone subgrade

Always state difference can reflect the cooling effect of crushed rock subgrade, when gravel basis values than ordinary road value basis, indicating the gravel roadbed cooling effect than ordinary embankment significantly. From figure 5 that the gravel roadbed depth above $5 \mathrm{~m}$ temperature decreased, the cooling rate and the gravel roadbed than ordinary embankment. Increase in the temperature below $5 \mathrm{~m}$ depth, but ordinary roadbed temperature rise than gravel base, shows that the cooling effect of crushed rock subgrade is obvious.

\section{CONCLUSION}

The gravel road base table under the temperature of the outside temperature changes greatly, when the outside temperature is low, the gravel road base temperature is low; when the outside air temperature is high, the gravel road base temperature is higher. In the gravel roadbed, along with depth, the temperature change has a certain lag. Compared with ordinary subgrade, gravel roadbed in the cold season and warm season has a cooling effect, the cooling effect of near surface distance is more obvious.

\section{ACKNOWLEDGMENTS}

This work was financially supported by National Science and Science Technology fund. The project name are Study on Deformation Characteristics of Loose Accumulation Subgrade Based on Hydraulic Coupling Mechanism (project number:310821162012)and Strong Weathering Phyllite Filling Road based Water Stress Coupling and Long-term Deformation Characteristics Research(project number: 211021130246.)

\section{REFERENCES}

[1] Yu Qihao, Qian Jin, You Yanhui. Experimental study on convection characteristics of block stone embankment [J]. Journal of Glaciology and Geocryology, 2012,34 (2):411-417.

[2] Wu Qingbai, Dong Xian Fu, Jiang Guanli. Open and closed block stone embankment under the condition of lower soil temperature [J]. Chinese Journal of rock mechanics and engineering effect difference, 2006,25 (12): 2565-2571.

[3] Chen Lin, Yu Wen Bin.Effect of aeolian sand on cooling effect of crushed stone embankment of Qinghai Tibet Railway[J].Journal of Glaciology and Geocryology,2015,(01):147-155. 